Guseinov K., Kudryavtsev O.A., Sapozhnikov S.B. Effectiveness of 2-D and 3-D modelling of dovetail joint of composite fan blade for choosing rational reinforcement schemes. PNRPU Mechanics Bulletin, 2021, no. 1, pp. 5-11. DOI: 10.15593/perm.mech/2021.1.01

ВЕСТНИК ПНИПУ. МЕХАНИКА

№ 1, 2021

PNRPU MECHANICS BULLETIN

https://ered.pstu.ru/index.php/mechanics/index

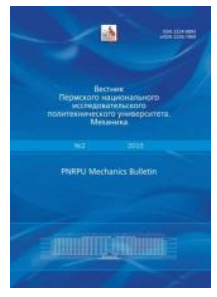

DOI: $10.15593 /$ perm.mech/2021.1.01

UDC 629.7.036.3, 539.419

\title{
EFFECTIVENESS OF 2-D AND 3-D MODELLING OF DOVETAIL JOINT OF COMPOSITE FAN BLADE FOR CHOOSING RATIONAL REINFORCEMENT SCHEMES
}

\author{
K. Guseinov*, O.A. Kudryavtsev, S.B. Sapozhnikov
}

South Ural State University, Chelyabinsk, Russian Federation

\section{ARTICLE INFO}

Received: 20 October 2020

Accepted: 22 March 2021

Published: 15 April 2021

\section{Keywords:}

digital twin, aircraft jet engine, composite fan blade, dovetail joint, numerical simulation, strength analysis, Daniel criterion.

\begin{abstract}
Turbofan jet engines are among the most complex and responsible constructions in the world. The creation of modern globally competitive engines is impossible without the use of digital twin technologies: a set of computational models that fully describe the behaviour of the structure under any operating conditions. Today, composite materials are widely used in many industries. In aircraft engines, their use is very promising for fan blades and fan case to reduce the overall weight of the engine and inertial loads. The dovetail joint of the fan blade works in compound stress conditions. To assess the strength of this element, it is necessary to consider a three-dimensional formulation of the problem, which requires significant computational resources. The use of composite materials is complicated by the complexity of preparing mesh models. A correct choice of the material strength criterion is another important factor that must be taken into account during the analysis of the mechanical behaviour of the thick-walled composite structures. The chosen criterion largely determines the reliability and weight efficiency of the composite structure. This paper considers the possibility of replacing the three-dimensional statement of the problem with a two-dimensional one when choosing rational reinforcing schemes for the dovetail joint of a CFRP fan blade at the initial stages using Daniel strength criterion.
\end{abstract}

๑ Kirill Guseinov - PhD student, e-mail: guseinovk.susu@gmail.com, iD: 0000-0001-9090-2582.

Oleg A. Kudryavtsev - CSc in Technical Sciences, Research Engineer, e-mail: kudriavtcevoa@susu.ru,

iD: 0000-0002-8530-3128.

Sergei B. Sapozhnikov - Doctor of Technical Sciences, Professor, e-mail: sapozhnikovsb@susu.ru, iD: 0000-0002-7022-4865. 


\section{Introduction}

Today, numerical modelling is widely used to create any technical product. The concept of digital twins allows combining all numerical models into a single complex that fully reflects the processes associated with the operation of the product and its response to any external influences. The use of this concept can significantly reduce the time and cost of product development by reducing the number of prototypes and design changes at later design stages [1].

Modern aircraft engines are extremely complex systems that must satisfy the highest requirements for reliability and fail-safety. The development of a globally competitive aircraft engine is impossible without the creation and wide using of its digital twin at all stages of design, production and operation. The tasks of ensuring the strength of engine elements require the use of appropriate numerical models, which are an integral part of the digital twin of the engine. One of the important problems is to ensure the strength and stiffness of the wide-chord fan blade. Wide-chord fan blades of promising foreign engines of a new generation like GEnx, UltraFan, LEAP and HF 120 are made of carbon fibre reinforced plastic (CFRP) since its use can significantly reduce the engine weight and improve the performance $[2,3]$. Currently, there is an active introduction of composite materials in the fan design of the latest domestic engines PD-14 and PD-35 [4-8]. Ensuring the strength of the dovetail joint of the composite fan blade requires a large number of computational and experimental studies [9, 10]. Strength calculation of blades using three-dimensional models (3-D calculation) allows taking into account the features of the problem with the necessary accuracy. However, the use of a two-dimensional problem statement (2-D calculation) can significantly reduce the calculation time when selecting reinforcement schemes at the initial design stage. Besides, a compound stress state is realized in the blade root during engine operation, it is necessary to apply strength criteria that take into account a possible decrease or increase of material strength under the simultaneous action of transverse normal and interlayer shear stresses.

In this work, the possibility of selecting rational schemes for reinforcing the dovetail root of the composite fan blade using 2-D models is considered using Daniel strength criterion. This criterion allows to take into account a change of the composite shear strength due to transversal compression. To check the results, similar calculations were performed using 3-D models. The results of the computational study showed that the use of a 2-D formulation of the problem allows obtaining adequate results in a significantly shorter time.

\section{Problem statement}

Dovetail root is most often used to connect wide-chord fan blades with an engine rotor (Fig. 1). The composite dovetail root is a thick-walled multilayer structure with a complex reinforcement scheme. It is necessary to take into account the effect of interlayer shear and transverse normal stresses on the quasi-static strength since they can lead to delamination and following fracture of the thick-walled composite. According to [11-15], interlayer stresses at the places of layers kink (in the root section) may be decisive for assessing the performance of the entire structure due to the low interlayer strength of CFRP.

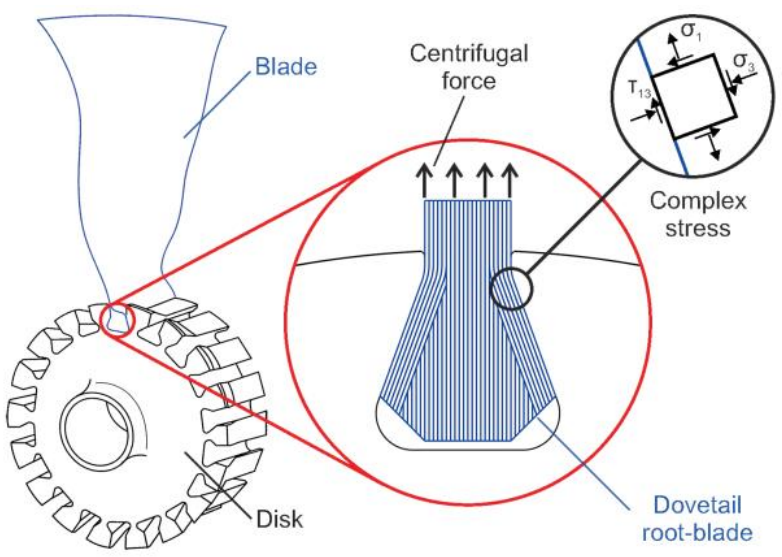

Fig. 1. Dovetail joint of the composite fan blade and the jet rotor

Many criterion dependences have been proposed [16-20] to describe the change of the composite strength under the simultaneous action of transverse normal and interlayer shear stresses (Fig. 2).

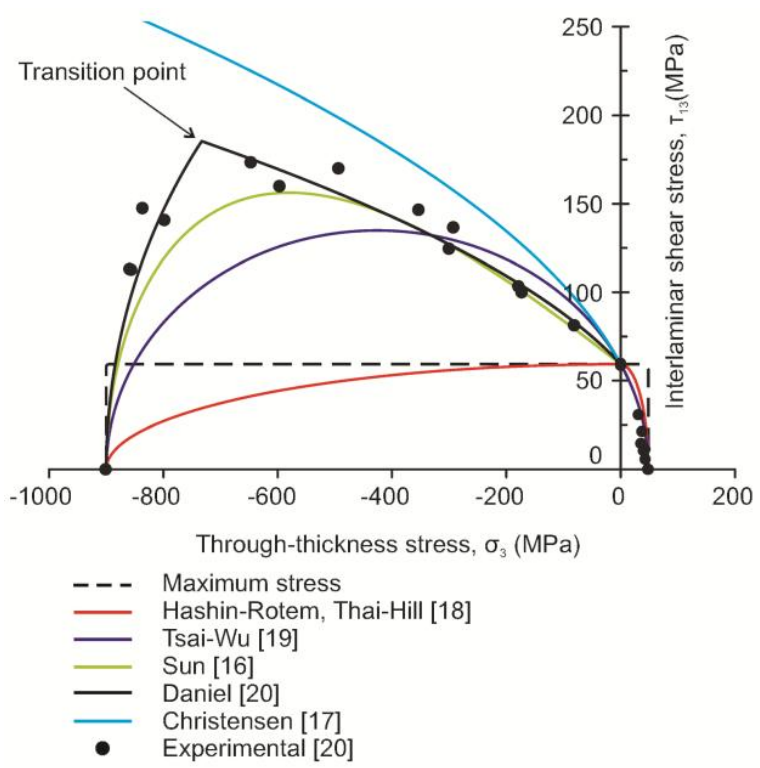

Fig. 2.Comparison of the experimentally obtained composite strength data for a simultaneous action of transverse normal and interlayer shear stresses with predictions of different criteria

The criterion of maximum stresses has become widespread in engineering practice for solving this kind of problems [12-15] due to its simplicity. However, the criterion does not take into account the combination of transverse and interlayer stresses and consider fracture from compression and shear separately. At the same time, a strength assessment obtained by the criterion of maximum 
stresses is very conservative at significant compressive stresses. Fan blade weight is an extremely important parameter, and it is necessary to use the full strength potential of the composite. For this reason, it is more promising to use Daniel criterion [20-22], which showed a good agreement with the experimental data (see Fig. 2). The small number of parameters requiring identification is an additional advantage of this criterion.

Daniel criterion is given as follows:

for transverse compression fracture mode,

$$
\left(\frac{\sigma_{3}}{F_{3 C}}\right)^{2}+\left(\frac{E_{3}}{G_{13}}\right)^{2} \cdot\left(\frac{\tau_{13}}{F_{3 C}}\right)^{2} \leq 1,
$$

for interlaminar shear fracture mode,

$$
\left(\frac{\tau_{13}}{F_{13}}\right)^{2}+2 \frac{G_{13} \cdot \sigma_{3}}{E_{3} \cdot F_{13}} \leq 1,
$$

where $\sigma_{3}$ is normal transverse stresses, $\tau_{13}$ is interlaminar shear stresses, $F_{3 \mathrm{C}}$ is transverse compressive strength, $F_{13}$ is interlaminar shear strength, $E_{3}$ and $G_{13}$ are transverse elastic modulus and interlaminar shear modulus, respectively.

The behaviour of the composite material in pure shear tests demonstrates significant nonlinearity [34]. Nonlinear behaviour of the material is caused by the progressive damage accumulation (matrix cracking, interlaminar failure, fibre fracture) and leads to a gradual stiffness decrease. To investigate the progressive failure of composite laminates, it is first necessary to predict accurately the load that will initiate the damage accumulation process. All damage accumulation models can be effectively implemented only in this case. In this regard, Daniel's criterion for composites has been revised as a set of yield criteria. In [21, 22], matrix yielding is defined as the initiation of the failure process in composite laminate. Macroscopically, the yield stress is the point at which the relative stiffness of material begins to decrease significantly and the behaviour of the material becomes non-linear. If $F_{3 \mathrm{C}}, F_{13}$ are defined as stresses limiting the linear elastic behaviour of the material, then it is quite acceptable to use the linear theory of elasticity. In this case, the ultimate load corresponds to the moment of the damage accumulation beginning, which is expressed in the significant nonlinearity of the mechanical behaviour and leads to delamination. This approach, of course, is conservative, but it avoids the use of complex and difficultto-verify models at the initial design stages.

The blade root has a precisely complex shape, and it is necessary to take into account the presence of contact between the root and the rotor disc. An analytical approach for the strength assessment is not applicable in this case due to the problem complexity. Therefore, numerical analysis using finite element method (FEM) is used at all design stages.

It is worth to mention that it is fundamentally impossible to take into account all features of the real product even using the most advanced CAE programs.
More important factors are taken into account, and less important ones are discarded. Engineers replace a real object with its numerical model, which includes geometry, material models, loads and boundary conditions. The choice of a numerical model is a complex, non-formalized problem of finding a compromise between the accuracy of modelling, the complexity of geometry preparing, and computational time.

2-D or 3-D geometric models can be used for the blade root design. In comparative calculations of the blade root made of traditional titanium alloys, the authors prefer 3-D formulation of the problem [23-27]. It is possible to estimate the contact stresses correctly in this case. In [27], the authors concluded that the use of a 3-D problem statement is necessary only at the edges of the joint. There is no need to determine the contact stresses accurately in the case of composite because this material is not subjected to fretting corrosion. It is also worth noting that the fracture in the composite dovetail root will occur outside the zone of contact stresses localization [28].

An important feature of the components made of composite materials is the relationship between the structure of the material, manufacturing technology and the strength of the finished product. It is necessary to perform not only checking calculation with known lay-up parameters but also design modelling for choosing rational reinforcement schemes. The use of full-size 3-D models in both cases will lead to a significant increase in development time. It is more rational to use 2-D models at the early stages of design because they are easily applicable for multi-parameter and multi-criteria optimization of layers staking sequence in a short time. Checking calculations with 3-D model could be done after the selection of the main reinforcement parameters. This strategy will accelerate the development of a digital twin of a product without compromising its predictive capabilities.

It is necessary to carry out strength analysis of the composite dovetail root using 2-D and 3-D models with different lay-ups to check the correctness of the proposed strategy. In both cases, Daniel's strength criterion must be used to take into account the effect of the compound stress state on the material's strength.

\section{Models description}

Loading of the composite dovetail root is a boundaryvalue problem of the mechanics of a deformable orthotropic-elastic solid. The virtual work principle in a weak form based on minimization of Lagrangian functional was used for the mathematical formulation of this problem:

$$
\delta \Pi=\int_{V} \sigma_{i j} \delta \varepsilon_{i j} d V-\int_{S} F_{i} \delta u_{i} d S-\int_{V} \rho a(r) \delta u_{i} d V=0 .
$$

Here, $\sigma_{i j}$ and $\varepsilon_{i j}$ are components of elastic stresses and strains tensors, $u_{i}$ and are components of displacements vector, $a(r)=\omega^{2} \cdot r$ is centripetal acceleration, $\omega$ is angular ve- 
locity of the rotor, $r$ is the distance from the disk rotation axis to the considered elementary volume, $F_{i}$ is a vector of surface forces, $V$ is a volume of deformable solids, $S$ is an area subjected to surface forces. More details could be found in [29]. In this work, the term in Equation (3), which is responsible for the inertial forces, was not considered for two reasons. First, the inertial forces acting on the dovetail root are much smaller in comparison with the resultant centrifugal forces from the blade. Second, correct consideration of the inertial forces acting on the dovetail root also requires determining the relationship between centripetal acceleration and centrifugal forces applied to the blade root. When choosing rational reinforcement schemes at the initial design stage, there are no accurate data on the mass and size characteristics of the working part of the fan blade. In this case, it is more rational to carry out comparative calculations in which the maximum allowable force in the root section is determined.

Numerical solution of equation (3) was carried out by the finite element method using ANSYS Workbench R1 2020 software with an implicit time integration scheme. Recommendations of the research works [23-27] devoted to the strength analysis of the dovetail joint were taken into account during the preparation of the numerical model. All calculations were performed using workstation based on Intel Xeon E5-2680 (2.5 GHz frequency, 24 cores, 48 logical processors) with 256 GB RAM.

\subsection{Mesh models}

The dimensions and shape of the composite dovetail root (Fig. 3) describe in [30] were used as initial data for the geometry preparing.

Two variants of the dovetail root mesh models were developed: two-dimensional (Fig. 4,a) and threedimensional (Fig. 4, $b$ ). In both cases, a homogeneous approach [31] was applied without explicit consideration of the layered structure of the material.

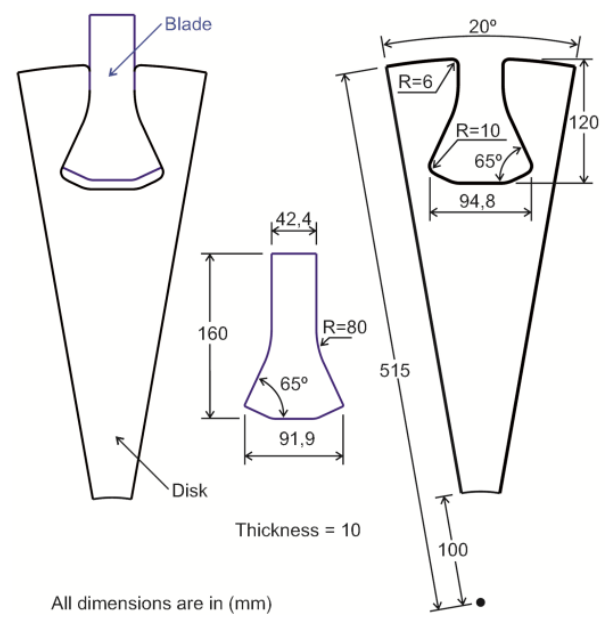

Fig. 3. The geometry of the fan blade dovetail joint

The orthotropy of the composite requires the correct orientation of the material axes in the direction of the warp and weft. Based on the data of [32-33], two typical variants of carbon fabric lay-up were selected for analysis (Fig. 5).

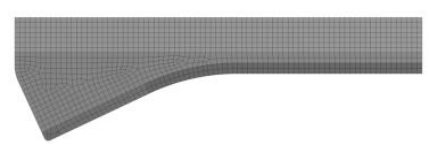

$a$

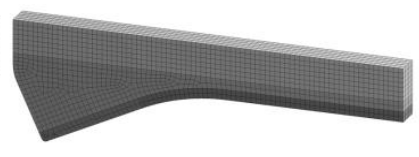

$b$
Fig. 4. Two-dimensional (a) and three-dimensional (b) mesh models of the composite dovetail root with an average finite element size of $2 \mathrm{~mm}$

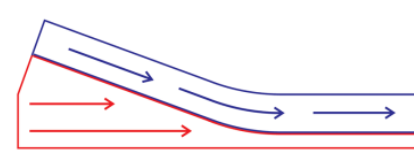

$a$

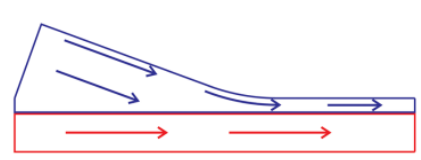

$b$
Fig. 5. Schemes of the lay-ups \#1 (a) and \#2 (b)

The orientation of material axes by default does not match the direction of the boundaries of finite elements. It is necessary to use different tools, for example, command inserts for orienting the material axes in the elements. It requires the creation of several coordinate systems and inconvenient for further evaluation by the strength criterion. The simplest way to orient properties along curved geometry is to use the Element Orientation tool in ANSYS Workbench. One layer of high-order solid-state finite elements SOLID186 was used to simulate a 2-D problem, whereas 20 elements through the thickness were used in a 3$\mathrm{D}$ analysis.

\subsection{Material properties}

CFRP is among the most promising material for the manufacture of fan blades. This material has the stiffness comparable with common titanium alloys but significantly surpasses them in terms of specific strength. The material was assumed orthotropic elastic (Table 1). The fracture parameters of the material used in Daniel criterion are presented in Table 2.

The linear elastic material model with the elastic modulus of $E_{\mathrm{S}}=200 \mathrm{GPa}$ and Poisson's ratio of $\mu_{\mathrm{S}}=0,3$ was utilised to simulate the mechanical behaviour of the steel disc.

Table 1

Elastic and strength properties of the CFRP single layer [34]

\begin{tabular}{|c|c|c|c|c|c|c|c|c|}
\hline $\begin{array}{c}E_{1}, \\
\mathrm{GPa}\end{array}$ & $\begin{array}{c}E_{2}, \\
\mathrm{GPa}\end{array}$ & $\begin{array}{c}E_{3}, \\
\mathrm{GPa}\end{array}$ & $\begin{array}{c}G_{12}, \\
\mathrm{GPa}\end{array}$ & $\begin{array}{c}G_{13}, \\
\mathrm{GPa}\end{array}$ & $\begin{array}{c}G_{23}, \\
\mathrm{GPa}\end{array}$ & $\mu_{12}$ & $\mu_{13}$ & $\mu_{23}$ \\
\hline 78 & 78 & 13.3 & 6.5 & 5.1 & 4.1 & 0.07 & 0.085 & 0.064 \\
\hline
\end{tabular}

Table 2

Strength properties of the CFRP single layer [34]

\begin{tabular}{|c|c|}
\hline$F_{3}, \mathrm{MPa}$ & $F_{31}, \mathrm{MPa}$ \\
\hline 812.8 & 74.8 \\
\hline
\end{tabular}




\subsection{Loads and boundary conditions}

The boundary conditions for the composite dovetail root were taken into account as follows (Fig. 6):

- The cyclic symmetry condition was set on the meridional planes bounding the disk sector and the fan blade root (1/36 part of the disc).

- Radial displacements were prohibited on the inner radius $\mathrm{R}_{1}$ of the disc.

- The contact type Frictionless (without friction) with Augmented Lagrange formulation was used between the disc and the fan blade root.

- Parts of the composite roots with different material axes orientations had common nodes.

A displacement was implemented to simulate the centrifugal load from the working part of the blade. The displacement value was increased until the destruction according to Daniel criterion was achieved. Daniel's criterion was specified through the User Defined Result module.

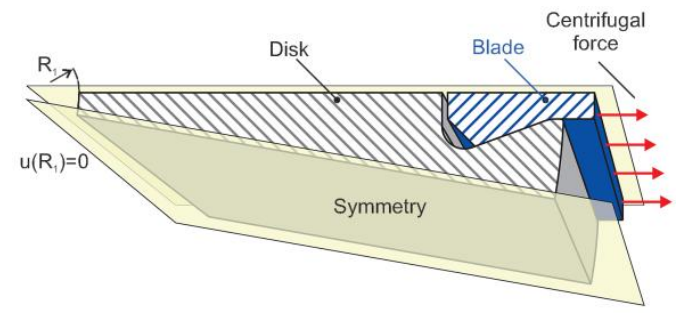

Fig. 6. Boundary conditions being considered

\subsection{Mesh convergence study}

The dependence of the maximum shear stresses on the characteristic size (length of the side of the cube) of finite elements (FE) is shown in Fig. 7. It is seen that the value of shear stresses with decreasing FE size tends to a constant value.

Based on the results of the convergence study, twodimensional and three-dimensional mesh models with a FE size of $0.5 \mathrm{~mm}$ were selected. The total number of elements in the models was 21338 and 428240 for 2-D and 3-D mesh models, respectively.

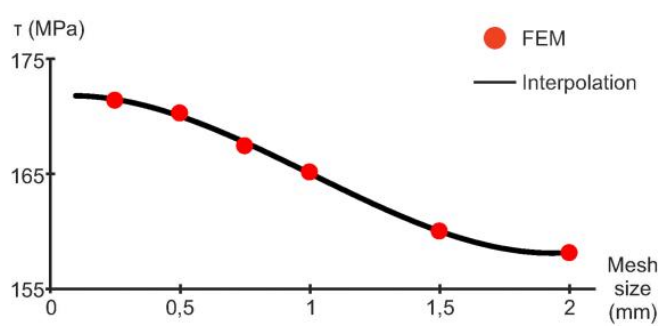

Fig. 7. Dependence of the maximum shear stresses on the edge length of the finite element

\section{Results and discussion}

The cut-and-try method was used to obtain the maximum displacement led to root failure in accordance with Daniel criterion for both fabric lay-ups. The strength assessment was carried out based on the analysis of stress fields in the layer coordinate system.

Stress analysis in the 3-D model showed that the maximum shear stresses (Fig. 8) are localized in the zone of transition from one type of fibre orientation to another, while the maximum transverse stresses (Fig. 9) are localized in the zone of contact between the fan blade root and the disk.

The distributions of Daniel criterion values obtained using the 3-D model for two lay-ups are shown in Fig. 10. Maximum fracture loads value according to Daniel's criterion was $11.47 \mathrm{MN} / \mathrm{m}$ (load per unit of thickness) and 13.1 MN/m for lay-ups 1 and 2, respectively. It can also be seen (see Fig. 10, $b$ ) that the fracture localised on the free surface of the root for lay-up \#2, and there are no significant shear stresses in the danger area. The corresponding damage mode, in this case, is fracture due to compression. Thus, lay-up \#2 should be excluded from consideration.

For lay-up \#1, a comparison with 2-D model results was performed. The interlayer shear and transverse compressive stresses in the danger area for the 3-D model were $170.5 \mathrm{MPa}$ and $408.1 \mathrm{MPa}$, whereas the 2-D model predicted the values $168.9 \mathrm{MPa}$ and $397.9 \mathrm{MPa}$, respectively. The difference in the stresses between the models did not exceed 5\%. The distributions of Daniel criterion values for lay-up \#1 obtained with 2-D (Fig. 11) and 3-D (Fig. 10, a) models fully confirm this conclusion. It is important to note that the interlayer shear and transverse compressive stresses remain almost constant throughout the entire thickness of the root in the danger area. Thus, the stresses in the fracture zone weakly depend on the type of stress state throughout the fan blade root thickness.

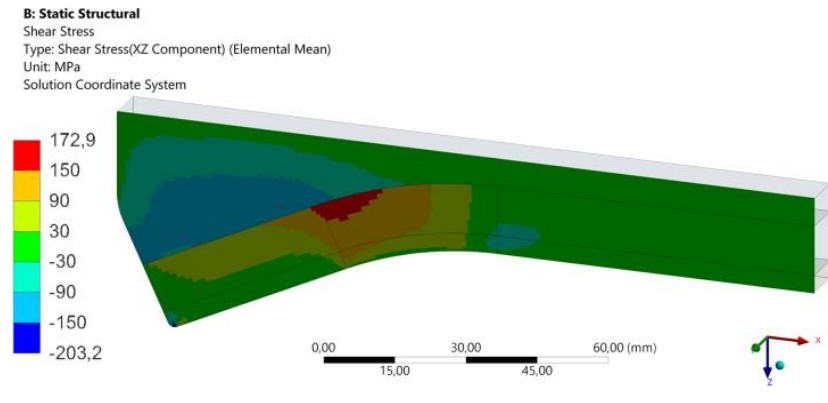

$a$

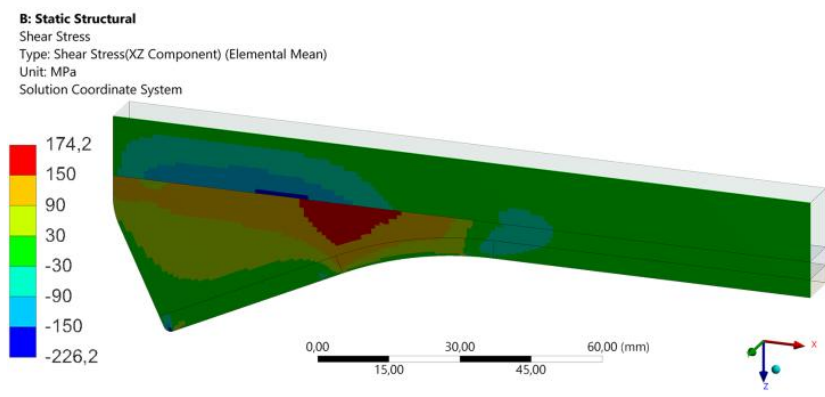

$b$

Fig. 8. Interlaminar shear stresses for 3-D model: a) lay-up \#1; b) lay-up \#2 


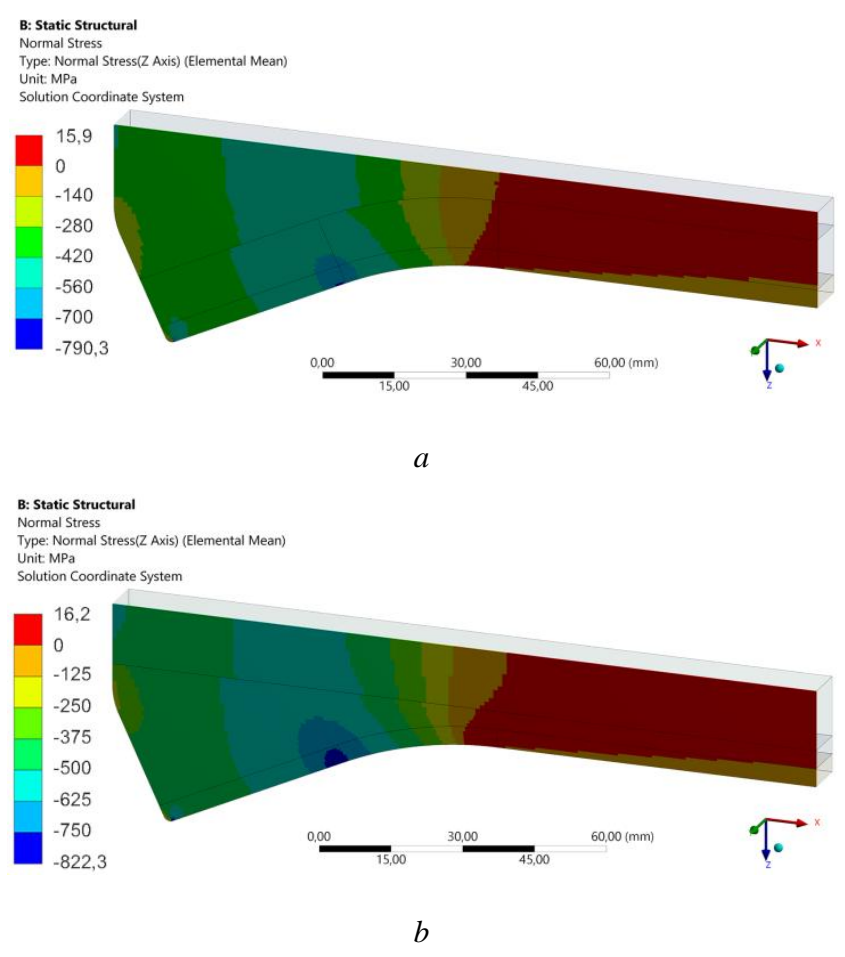

Fig. 9. Transverse normal stresses for 3-D model: a) lay-up \#1; b) lay-up \#2

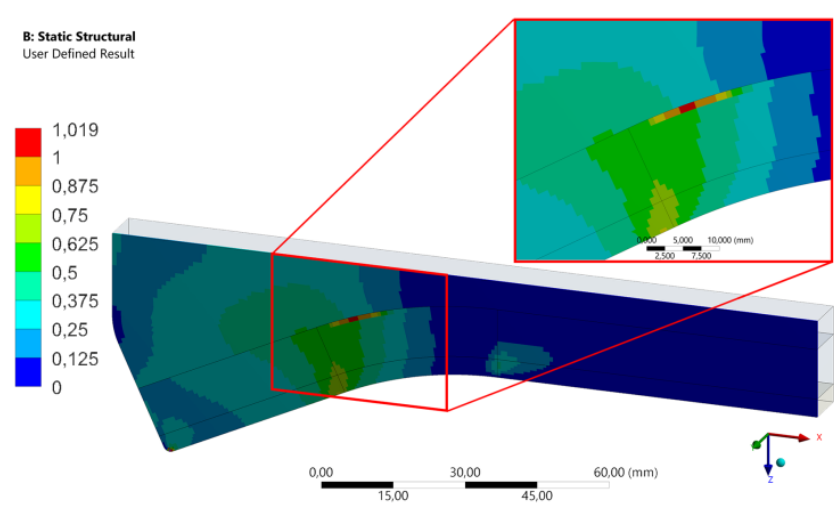

$a$

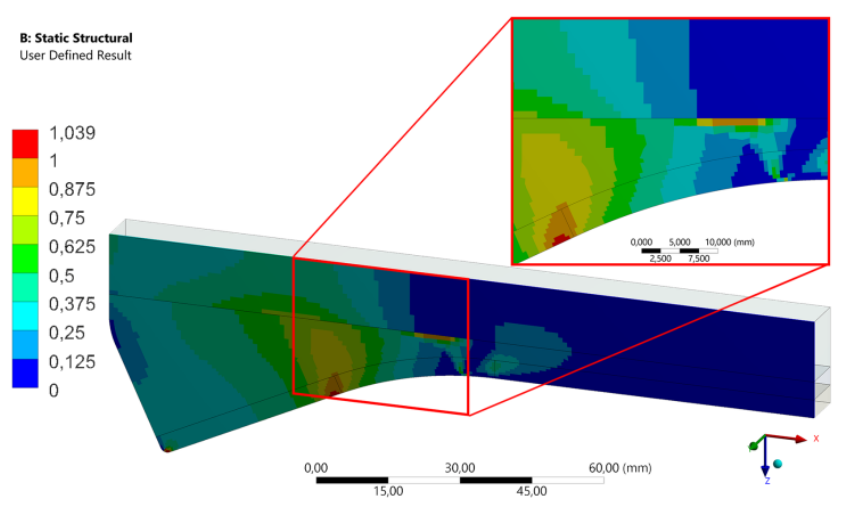

$b$

Fig. 10. The distributions of Daniel criterion values obtained using the 3-D model: a) lay-up \#1; b) lay-up \#2

The 3-D and 2-D models gave similar results, but the computation time when using the 3-D model was $2795 \mathrm{~s}$, while for the 2-D model this parameter did not exceed $79 \mathrm{~s}$.
Thus, the computing time was reduced by more than 35 times! This is an indisputable advantage of using 2-D models when selecting the optimal reinforcement schemes using external optimizers, for example, IOSO or pSeven.

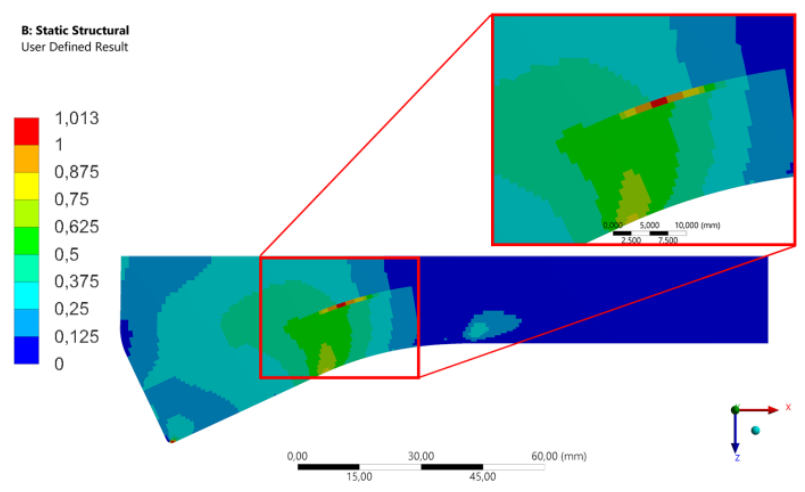

Fig. 11. The distributions of Daniel criterion values for lay-up \#1 obtained using the 2-D model

The increase in shear strength and maximum load due to the transition to the assessment of strength from the maximum stress criterion to Daniel's criterion was $240 \%$. (Fig. 12).

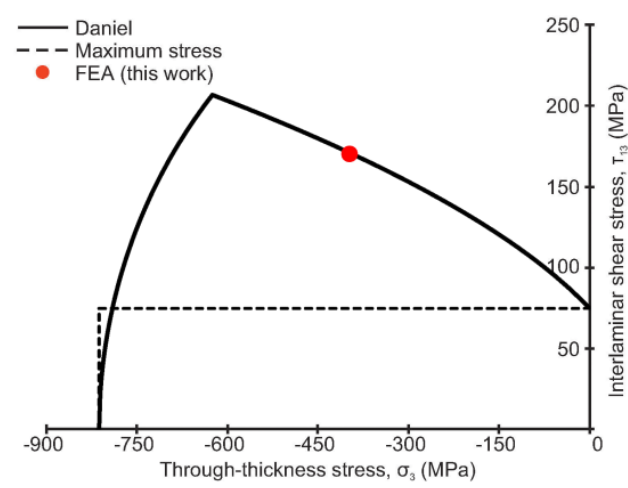

Fig. 12. Fracture surfaces with computational points

It should be noted that lay-up \#1 was not yet optimal (see Fig. 12). The choice of the optimal reinforcement scheme for the realization of maximum shear strength according to Daniel criterion will be the subject of future work. The obtained safety factor characterizes only the beginning of the delamination of one or more layers that may not lead to the full fan blade fracture. After the first delamination, the load is redistributed to the undamaged layers with different reinforcement angles. It is possible that a new stress-strain state can satisfy the strength criterion, and the overall performance of the structure will be kept.

\section{Conclusion}

Developing a digital twin of a complex technical product requires a significant investment of time and resources at the design stage. Numerical models for assessing structural strength are an integral part of the digital twin. In this work, the possibility of replacing 3-D computational models for assessing the strength with 2-D ones at the initial stages of designing wide-chord CFRP blades of turbofan jet engines was considered. 
It was found that the use of 2-D computational models makes it possible to analyse the effectiveness of various schemes for reinforcing the blade root using identical strength criteria, in particular, Daniel criterion without loss of accuracy.

An important advantage of using 2-D models is a significant reduction in the computation time and the relative simplicity of geometry preparation, which makes it possible to use various optimization tools widely. In the

\section{References}

1. Borovkov A.I., Maruseva V.M., Ryabov Yu.A. A new paradigm of digital design and modelling of globally competitive products of the new generation. Working report of the Department of Corporate Education of the Moscow School of Management Skolkovo «Digital Production: Methods, Ecosystems, Technologies». Available: http://assets.fea.ru/uploads/fea/news/2018/04_april/12/cifrovoe-proizvodstvo-032018.pdf.

2. Anoshkin A.N., Zuiko V.Yu., Shipunov G.S., Tretyakov A.A. Technologies and problems of composite materials mechanics for production of outlet guide vane for aircraft jet engine. PNRPU Mechanics Bulletin. 2014, no. 4, pp. 5-44.

3. Karimbaev T.D., Luppov A.A., Afanasiev D.V., Palchikov D.S. On the formation of technical requirements for a polymer material of a promising fan blade of a turbofan engine. Engine. 2015, no. 1(97), pp 4-10

4. Karelin O.O., Koltyrina K.Y. Employment of composite materials in aero-engine manufacturing. Bulletin of P.A. Solovyov Rybinsk State Aviation Technical University. 2015, no. 2(35), pp. 53-59.

5. Karimbaev T.D., Luppov A.A., Afanasiev D.V. CF composite fan rotor blading for perspective engines. Engine. 2011, no. 6(78), pp. 2-9.

6. Rubcov S.M. Primenenie sovremennyh polimernyh kompozicionnyh materialov $\mathrm{v}$ ehlementah i uzlah gazoturbinnyh aviacionnyh dvigatelej: dissertaciya na soiskanie uchenoj stepeni k.t.n: 05.02.01, Perm' 2009, 140p.

7. Grinev M.A., Anoshkin A.N., Pisarev P.V., Zuiko V.Yu., Shipunov G.S. CAD/CAE modelling of mechanical behavior of composite outlet guide vane for aircraft jet engine. PNRPU Mechanics Bulletin. 2015, no. 3, pp. 38-51.

8. Grinev M.A., Anoshkin A.N., Pisarev P.V., Zuiko V.Yu., Shipunov G.S. Stress-strain analysis and strength prediction of composite outlet guide vane for aircraft jet engine. PNRPU Mechanics Bulletin. 2015, no. 4, pp. 293-307.

9. Novikov A.S., Karimbaev T.D., Luppov A.A., Afanasiev D.V., Mezentsev M.A. Innovation in the use of composite materials in aircraft engines. Engine. 2015, no. 2(98), pp. 8-11.

10. Novikov A.S., Karimbaev T.D. Large bypass fan blades for advanced turbojet engines. Engine. 2015, no. 5(101), pp. 6-11.

11. Wang Y., Soutis C., Hajdaei A., Hogg P.J. Finite element analysis of composite $\mathrm{T}$-joints used in wind turbine blades. Plastics, Rubber and Composites. 2015, vol. 44, iss. 3, pp. 87-97.

12. Anoshkin A.N., Tashkinov A.A. Prognozirovanie nesushchej sposobnosti kompozitnyh flancev korpusnyh detalej aviadvigatelej. Perm': Izd-vo PGTU, 1998. 101 p.

13. Anoshkin A.N., Tashkinov A.A. Nonsteady-state damage accumulation processes in composite flanges under cyclic loads. Mechanics of Composite Materials. 1997, vol. 33, no. 5, pp. 449-454.

14. Anoshkin A.N., Rudakov M.V., Straumit I.S., Shustova E.N. Raschet nds i ocenka prochnosti kompozitnogo flanca stekloplastikovogo kozhuha aviacionnogo gazoturbinnogo dvigatelya. Vestnik UGATU. 2011, vol. 15, no. 1(41), pp. 67-75.

15. Anoshkin A.N., Rudakov M.V., Straumit I.S., Grinev M.A. Modeling the mechanical tests of composite flange samplesegment from aircraft engine cover. Izvestia of RAS SamSC. 2011, vol. 13 , no.1-2, pp. $283-288$.

16. Sun C.T. Strength analysis of unidirectional composites and laminates. In: Comprehensive Composite Materials, Kelly A. and Zweben C. (Eds). Oxford: Elsevier Science Ltd., 2000, pp. 641-666. considered case, the total CPU time was reduced from 2795 to 79 sec. Once a rational reinforced scheme has been obtained, more detailed calculations can be done on a fullsize 3-D model for the final selection of all dimensions.

\section{Acknowledgement}

This work was financially supported by the Russian Science Foundation (project No. 18-19-00377).

17. Christensen R.M., DeTeresa S.J. Delamination failure investigation for out-of-plane loading in laminates. Journal of Composite Materials. 2004, vol. 38, no. 24, pp. 2231-2238.

18. Hill R. The Mathematical theory of plasticity. Science, $1998.355 \mathrm{p}$.

19. Tsai S.W., Wu E.M. A General Theory of Strength for Anisotropic Materials. Journal of Composite Materials. 1971, vol. 5 , no. 1 , pp. $58-80$.

20. Daniel I.M. Failure of composite materials. Strain. 2007, vol. 42, no. 1, pp. 4-12.

21. Daniel I.M. Yield and failure criteria for composite materials under static and dynamic loading. Progress in Aerospace Sciences. 2016, vol. 81, pp. 18-25.

22. Daniel I.M., Daniel S.M., Fenner J.S. A new yield and failure theory for composite materials under static and dynamic loading. International Journal of Solids and Structures. 2018, vol. 148-149, pp. 79-93.

23. Anandavel K., Prakash R.V. Effect of three-dimensional loading on macroscopic fretting aspects of an aero-engine blade disc dovetail interface. Tribology International. 2011, vol. 44, no. 11 , pp. $1544-1555$.

24. Dave G.R., Krishaswamy R., Chadrappa L.M., Kulkarni K., Jain N. Design and Analysis of Crown Profile of Fan Rotor Blade Roots for Gas Turbines. In: Proc. of the ASME 2014 Gas Turbine India Conference, GTINDIA2014-8180. DOI: 10.1115/GTINDIA2014-8180.

25. Papanikos P., Meguid S.A., Stjepanovic Z. Threedimensional nonlinear finite element analysis of dovetail joints in aeroengine discs. Finite Elements In Analysis And Design. 1998, vol. 29 , no. 3-4, pp. 173-186.

26. Beisheim J.R., Sinclair G.B. On the three-dimensional finite element analysis of dovetail attachments. Journal of Turbomachinery. 2003, vol. 125, no. 2, pp. 372-379.

27. Beisheim J.R., Sinclair G.B. Three-dimensional finite element analysis of dovetail attachments with and without crowning. Journal of Turbomachinery. 2008, vol. 130, no. 2. pp. $1-8$.

28. Zhang B., Kawashita L.F., Jones M.I., Lander J.K., Hallet S.R. An experimental and numerical investigation into damage mechanisms in tapered laminates under tensile loading. Composites Part A: Applied Science and Manufacturing. 2020, vol. $133,105862$.

29. Bower A.F. Applied Mechanics of Solids. CRC Press, 2009. 820p.

30. Klinetob C.B., Huth B.P., Reinhardt G.E. Composite fan blade dovetail root. U.S. Patent 8,573,947 B2, 2013.

31. Kudryavtsev O.A., Zhikharev M.V., Olivenko N.A. Creation and verification of computational models for analysis of the mechanical behaviour of jet engines composite components under high-velocity impact: Main problems and basic recommendations. PNRPU Mechanics Bulletin. 2019, no. 4, pp. 68-79.

32. Bond N.M., Hemsworth M.C. Assembly of a composite blade root and a rotor. U.S. Patent 5,573,377, Nov. 12, 1993.

33. McCaffrey M.G. Root region of a blade for a gas turbine engine. U.S. Patent 8,794,925 B2, Aug. 5, 2014.

34. Abot J.L., Daniel I.M. Through-thickness Mechanical Characterization of Woven Fabric Composites. Journal of Composite Materials. 2004, vol. 38, no. 7, pp. 543-553. 